\title{
Representational pseudoneglect and reference points both influence geographic location estimates
}

\author{
Alinda Friedman $\cdot$ Christine Mohr $\cdot$ Peter Brugger
}

Published online: 13 January 2012

(C) Psychonomic Society, Inc. 2012

\begin{abstract}
Our mental representation of the world is far from objective. For example, western Canadians estimate the locations of North American cities to be too far to the west. This bias could be due to a reference point effect, in which people estimate more space between places close to them than far from them, or to representational pseudoneglect, in which neurologically intact individuals favor the left side of space when asked to image a scene. We tested whether either or both of these biases influence the geographic world representations of neurologically intact young adults from Edmonton and Ottawa, which are in western and eastern Canada, respectively. Individuals were asked to locate North American cities on a two-dimensional grid. Both groups revealed effects of representational pseudoneglect in this novel paradigm, but they also each exhibited reference point effects. These results inform theories in both cognitive psychology and neuroscience.
\end{abstract}

Keywords Spatial cognition · Cognitive neuroscience and attention · Neuropsychology $\cdot$ Hemi-spatial neglect .

Spatial memory

In cognitive psychology and human geography, it is well established that people have regionalized, hierarchical

\footnotetext{
A. Friedman $(\bowtie)$

Department of Psychology, University of Alberta, Edmonton, Alberta T6G 2E9, Canada

e-mail: alinda@ualberta.ca

C. Mohr

Institute of Psychology, University of Lausanne,

Lausanne, Switzerland

P. Brugger

Department of Neurology, University Hospital Zurich and Zurich

Center for Integrative Human Physiology (ZIHP),

Zurich, Switzerland
}

representations of the world (Friedman, 2009; Friedman \& Brown, 2000a, 2000b; Friedman, Kerkman, Brown, Stea, \& Cappello, 2005; Friedman \& Montello, 2006; Stevens \& Coupe, 1978). For example, when people estimate the latitudes of cities, they divide space into regions that do not overlap and are not necessarily coincident to political borders. Such estimates reveal relatively large gaps between regions that do not reflect the north-south intermingling of actual borders; the bias in the north-south estimates increases as the cities being estimated are actually farther south; and the regions can be influenced independently, depending upon whether they are "conceptually coordinated" (Friedman \& Brown, 2000b). These findings have been obtained with subjects who live in very different parts of North America (Friedman et al., 2005), using both numeric (Friedman \& Brown, 2000a, 2000b; Friedman \& Montello, 2006) and spatial (Friedman, 2009) response modes.

However, only the spatial response mode revealed how people placed cities on both latitude and longitude dimensions simultaneously, and the only subjects who have done so were western Canadians (Friedman, 2009). Whereas latitude estimates were again biased too far to the south, longitude estimates were biased too far to the west, and there was more "space" between western than eastern Canadian cities. The latter bias could have arisen because subjects were more familiar with western Canadian cities and/or a reference point near them (e.g., the Rocky Mountains). For example, Holyoak and Mah (1982) showed that Californians rated the magnitude of the imagined difference in east-west distance between two cities close to a reference point (e.g., the Pacific Ocean) to be greater than that between cities that were far from the reference point, even though the distances were actually equal. When a different group of Californians were asked to imagine they were on the east coast, the opposite result obtained: The east-west difference between cities close to the Atlantic 
Ocean was greater than that between western cities. Holyoak and Mah proposed that stimulus magnitudes that are closer to a reference point are easier to discriminate from each other than magnitudes that are far from it. The use of the reference point construct is ubiquitous across many areas of psychology (see, e.g., Kahneman \& Tversky, 1979). Thus, the western bias in Friedman's (2009) data might have been due to where the subjects happened to live (i.e., Edmonton).

There is another possibility, however: The neuropsychological phenomenon of hemispatial neglect, which occurs in both patient populations and healthy individuals. A vast literature documents this condition in patients with damage to mainly the right hemisphere; they demonstrate a deficit in directing their attention toward the left hemispace (for recent accounts, see Adair \& Barrett, 2008; Verdon, Schwartz, Lovblad, Hauert, \& Vuilleumier, 2010). For example, when patients with neglect judge the subjective midpoint of a horizontal line, they place their bisections to the right of the objective midpoint, as if they are ignoring the left side of space or are hypersensitive or more attentive to the right side of space. Even when asked to place familiar cities on a map of England (where this particular patient had lived), all of the cities were placed on the east coast of the map (Critchley, 1962). Similarly, a French patient with hemispatial neglect placed all of the cities in France on the east side of a map that was aligned with his body axis (Rode et al., 2010). These data are relevant to the present study because they illustrate that even when people are limited by the true boundaries of a given space, they exhibit hemispatial neglect. The absence of coexisting contralateral peripheral sensory or motor loss suggests that the impairment involves higher-level processes. In fact, it has been shown that preattentive processing up to the level of meaning can take place in the neglected field without conscious awareness (e.g., Driver \& Vuilleumier, 2001; Vallar, 1998).

Further evidence that neglect involves higher-level processes comes from studies on representational neglect, in which there is a deficiency of attention to the left side of imagined space. The seminal demonstration was reported by Bisiach and Luzzatti (1978): When asked to image (with eyes closed) and then describe the Piazza del Duomo in Milan, neglect patients reported far fewer landmarks on the left than on the right side. Famously, when asked to image the same Piazza from its opposite side, the phenomenon was the same: far fewer landmarks were reported on the left side (see also Rode et al., 2010). This finding is similar to the one from Holyoak and Mah (1982), and it implies that the imagined representation must have been "whole," but the processes used to read from it were impaired. Later work extended the findings to imagining the map of a country from a particular view (e.g., from the north vs. the south; Rode \& Perenin, 1994) and to more abstract spatialized stimuli (i.e., the number line; Vuilleumier, Ortigue, \& Brugger, 2004; Zorzi, Priftis, \& Umiltà, 2002).
Of relevance to the present study, in neurologically intact individuals, perceptual and imagined space are both also biased along the horizontal axis, but toward the opposite side of space as the patient populations. For example, when performing line bisections, healthy individuals show a slight but consistent bias to locate the subjective midpoint to the left of true center (thus ignoring the right side of the paper). This hemispatial bias is known as pseudoneglect (Bowers \& Heilman, 1980; Jewell \& McCourt, 2000) and is also thought to be modulated by higher-level processing (Mohr $\&$ Leonards, 2007). Finally, with respect to imagined space and representational pseudoneglect, McGeorge, Beschin, Colnaghi, Rusconi, and Della Sala (2007) replicated the Bisiach and Luzzatti (1978) experiment with healthy individuals who showed a bias to report fewer landmarks from the right side of the imagined scene (see also Loetscher \& Brugger, 2007).

In the present study, our goal was to explore the two possible explanations of the Edmontonian geographical estimates: (a) that the westward bias was due to a reference point effect, or (b) that it was due to representational pseudoneglect. We tested one group from Edmonton, Alberta (longitude $113^{\circ} \mathrm{W}$ ), and a second from Ottawa, Ontario (longitude $76^{\circ} \mathrm{W}$ ), who both made spatial location estimates of cities in North America. If the leftward bias of Edmontonians was due to a reference point effect alone, then we should see the opposite result in the Ottawans; that is, a rightward bias, and more space between eastern than western cities. This finding would have potential consequences for current neuropsychological theories of neglect. For example, if Ottawans show a reference point effect, it cannot be that they are completely neglecting the right-sided semantic or spatial information that implicitly or explicitly played a role in their responses. In contrast, if the previously observed leftward bias was due strictly to representational pseudoneglect, then we should see a similar leftward bias in the Ottawans' data. This would have potential consequences for any cognitive theory of location estimation. For example, if representational pseudoneglect causes part of the observed longitudinal bias, then theories of geographical location estimates that consider only metrics and mapping (Brown \& Siegler, 1993) or placing regions with respect to global landmarks (Friedman \& Brown, 2000a, 2000b) must be augmented to account for this neuropsychological factor. Finally, the processes may not be mutually exclusive: We could plausibly find evidence for both. For example, familiarity with one's home region could plausibly underlie the reference point effect, which could thus manifest itself even if a person also displayed pseudoneglect. A priori, we presumed that these are different mechanisms and that they might both be present.

It should be noted that for tasks that reveal representational neglect (neglecting the left side) or representational 
pseudoneglect (neglecting the right side), the assumed reference point is considered to be a body-centered one. For example, in the line bisection task or in previous map-based tasks, the line or map is assumed to be anchored to the subject's body-centered view (e.g., Halligan, Fink, Marshall, \& Vallar, 2003; Rode et al., 2010). Indeed, the paper to be drawn on in both cases is centered in front of the subjects, as is the computer screen in the present case. It is for this reason that we predict a westward shift (i.e., pseudoneglect) for both groups if, in fact, the westward shift is a manifestation of pseudoneglect. The theoretical and empirical question is whether the Ottawans will show a leftward (pseudoneglect only) or rightward (reference point only) shift, or whether instead they will have more space between eastern than western cities, yet at the same time show a western bias for most cities (including their own). The latter finding would indicate that both phenomena were underlying the estimates.

\section{Method}

Subjects: demographics and handedness

A group of 32 volunteers (15 female, 17 male) drawn from the University of Alberta's psychology subject pool (Edmonton, Alberta, Canada) received partial credit for their participation. Of the subjects, 27 were right-handed, and the remaining 5 were either ambidextrous or left-handed, according to a standardized handedness questionnaire (Oldfield, 1971). We examined handedness because it is an important factor in many cognitive asymmetries, although a metaanalysis of pseudoneglect (Jewell \& McCourt, 2000) showed that the effect was small on bisection errors, with righthanders erring slightly more to the left than did left-handers. We wanted merely to assure that the proportions were similar in both groups.

A further 30 volunteers (15 female, 15 male) drawn from the Carleton University psychology subject pool (Ottawa, Ontario, Canada) received partial credit for their participation. The task for the present study was performed as a "filler task" for a second, unrelated study about mathematical skills. Of these subjects, 25 were right-handed, and the remaining 5 were either ambidextrous or left-handed. Thus, the proportions of right- and left-handed individuals were approximately the same in each group, but there were too few left-handers to analyze separately.

Stimuli, design, and procedure

Subjects in both cities estimated the locations of 18 Canadian cities and 9 cities from each of the northern and southern U.S. and Mexico. Table 1 lists the cities and their actual latitudes and longitudes, and Fig. 1 shows their actual locations. To test
Table 1 The stimulus cities and their actual latitudes and longitudes

\begin{tabular}{|c|c|c|}
\hline Cities & Longitude (deg W) & Latitude (deg N) \\
\hline \multicolumn{3}{|l|}{ Canada } \\
\hline *Halifax & -64 & 45 \\
\hline *Fredericton & -67 & 46 \\
\hline *Quebec City & -71 & 47 \\
\hline *Ottawa & -76 & 45 \\
\hline *Toronto & -79 & 44 \\
\hline *Sault Ste Marie & -84 & 47 \\
\hline *Thunder Bay & -89 & 48 \\
\hline Churchill & -94 & 59 \\
\hline Winnipeg & -97 & 50 \\
\hline Brandon & -100 & 50 \\
\hline *Regina & -105 & 50 \\
\hline *Saskatoon & -107 & 52 \\
\hline *Fort McMurray & -111 & 57 \\
\hline *Edmonton & -113 & 54 \\
\hline$*$ Jasper & -118 & 53 \\
\hline *Kamloops & -120 & 51 \\
\hline *Vancouver & -123 & 49 \\
\hline *Prince Rupert & -130 & 54 \\
\hline \multicolumn{3}{|l|}{ Northern U.S. } \\
\hline Boston & -71 & 42 \\
\hline Detroit & -83 & 42 \\
\hline Chicago & -88 & 42 \\
\hline Minneapolis & -93 & 45 \\
\hline Lincoln & -97 & 41 \\
\hline Denver & -105 & 40 \\
\hline Great Falls & -111 & 48 \\
\hline Boise & -116 & 44 \\
\hline Seattle & -122 & 48 \\
\hline \multicolumn{3}{|l|}{ Southern U.S. } \\
\hline Miami & -80 & 26 \\
\hline Birmingham & -87 & 34 \\
\hline Jackson & -90 & 32 \\
\hline Houston & -95 & 30 \\
\hline San Antonio & -98 & 29 \\
\hline Albuquerque & -107 & 35 \\
\hline Phoenix & -112 & 33 \\
\hline Las Vegas & -115 & 36 \\
\hline Los Angeles & -118 & 34 \\
\hline \multicolumn{3}{|l|}{ Mexico } \\
\hline Cancun & -87 & 21 \\
\hline Mexico City & -99 & 19 \\
\hline Acapulco & -100 & 17 \\
\hline Puerto Vallarta & -105 & 21 \\
\hline Chihuahua & -106 & 29 \\
\hline Ciudad Juarez & -106 & 32 \\
\hline Mazatlan & -107 & 23 \\
\hline Cabo San Lucas & -110 & 23 \\
\hline Tijuana & -117 & 33 \\
\hline
\end{tabular}

The starred Canadian cities were used in the analyses related to the reference point effect. 


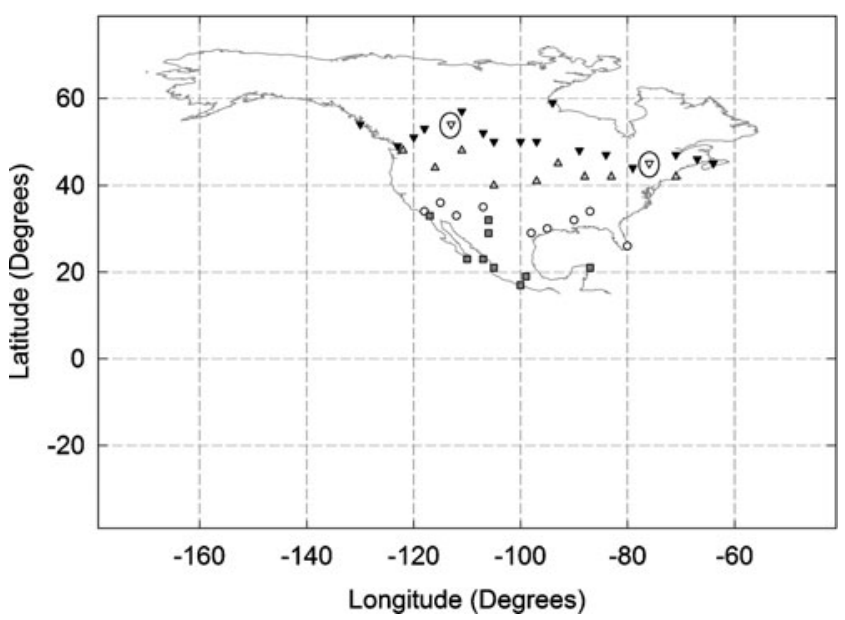

Fig. 1 The actual locations of the stimulus cities as a function of north-south region (Canada, black upside-down triangles; northern U.S., white right-side-up triangles; southern U.S., white circles; Mexico, gray squares). The upside-down white triangles in the approximate centers of the two circles in Canada are, from west to east, Edmonton and Ottawa. Note that the figure depicts only part of the stimulus array: The longitudes that appeared on each trial ranged from $0^{\circ}$ to $180^{\circ} \mathrm{W}$, and the latitudes ranged from $90^{\circ} \mathrm{N}$ to $40^{\circ} \mathrm{S}$

the main hypotheses, we were primarily interested in the longitude estimates for the Canadian cities; however, tests of the other regions were of interest for comparison to past research (e.g., Friedman, 2009; Friedman \& Brown, 2000a, 2000b).

After signing a consent form, all subjects were seated in front of a computer monitor with $1,024 \times 768$ pixel resolution. The latitude $\times$ longitude grid used the full $180^{\circ}$ range of longitudes, from $0^{\circ}$ (Greenwich, England) to $180^{\circ}$ (Pacific Ocean). This is important because, if subjects were merely trying to utilize all of the space available to them, then we would expect them to center their responses at about $90^{\circ} \mathrm{W}$. The latitudes on the grid ranged from $90^{\circ} \mathrm{N}$ (North Pole) to $40^{\circ} \mathrm{S}$ (about $6^{\circ}$ south of Buenos Aires, Argentina). A "use all the space" strategy would thus center the cities at about $65^{\circ} \mathrm{N}$. Each "box" in the grid was square and was labeled every $10^{\circ}$ of latitude/longitude.

Subjects first performed a knowledge rating task to familiarize them with the set of cities that they would be rating. The task specifically asked about general knowledge about each city, not specifically for spatial knowledge. On each trial, the name of a city, its state/province, and its country were presented on the monitor, and the subject responded by using the number pad to enter numbers from 0 (no knowledge) to 9 (a lot of knowledge).

Next, subjects were instructed about how latitudes and longitudes work. On each trial of the estimate task, an empty latitude $\times$ longitude grid appeared, along with the name of a city, its state or province, its country, and an $X$ at the top of the grid. The subject dragged the $X$ to the place on the grid where he or she thought the city was located. There were no time constraints. The subject then pressed the Enter key, and the next trial began. Each subject received a different random order of cities for both the knowledge rating and estimation tasks.

When the estimation task was finished, the subjects filled out the handedness questionnaire and answered two multiplechoice questions about the northern- and southern-most latitudes of North America, for comparison to previous research. The alternatives included the full latitude range, from $90^{\circ}$ to $90^{\circ}$, in $10^{\circ}$ steps, with the equator identified as such.

\section{Results and discussion}

For all statistical tests, we used $p<.05$ as the significance level, $\eta_{p}^{2}$ as the measure of effect size, and the $95 \%$ confidence intervals $(\mathrm{CIs})$ of the means computed from the withinsubjects error term (Masson \& Loftus, 2003) as the measure of variability. Figure 2 shows the data. It is apparent that the latitude estimates replicated characteristics of results we have obtained many other times (Friedman \& Brown, 2000a, 2000b; Friedman et al., 2005; Friedman \& Montello, 2006) and that there was evidence for both reference point effects and the traditional, body-centered effect of representational pseudoneglect.

Analyses of signed errors

We computed signed errors for both the latitude and longitude estimates for each city and subject by subtracting the estimated value from the actual value. On the north-south dimension, negative numbers are too far south; on the eastwest dimension, they are too far west, because in the Western Hemisphere longitudes are signed negatively.

For latitudes, a Group $\times$ Region analysis of variance (ANOVA) yielded only a main effect of region, $F(3,180)=$ $60.61, \eta_{p}^{2}=.503$ (all other $F_{\mathrm{s}}<1.0$ ). The mean values for estimates of cities in Canada, the northern United States, the southern United States, and Mexico were $-0.04^{\circ},-12.40^{\circ}$, $14.40^{\circ}$, and $-24.42^{\circ}\left(95 \% C I= \pm 3.53^{\circ}\right)$, respectively, replicating our previous results. The errors for both groups became too far south as the cities being estimated were actually located farther south. The groups also did not differ with respect to where they thought the northern and southern borders of North America were: Only the main effect of north/south was significant, $F(1,60)=243.21, \eta_{p}^{2}=.802$. On average, both eastern and western Canadians thought that the northern border of North America was at $77.1^{\circ}$ and the southern border was at $-6.5^{\circ}\left(C I= \pm 10.70^{\circ}\right)$. Thus, all of our previous results with latitude estimates were replicated in both groups here.

To test for representational pseudoneglect, we conducted two analyses of the signed errors in longitude estimates. The 


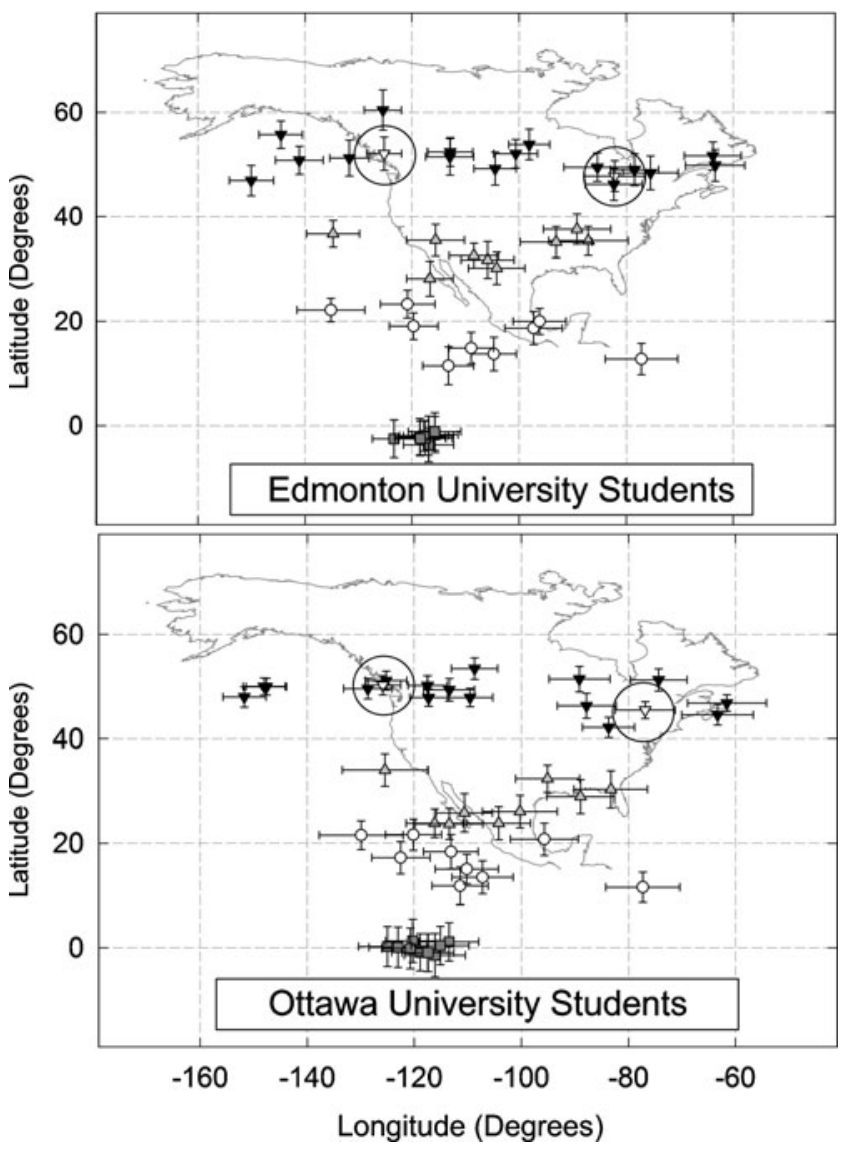

Fig. 2 The estimated locations of all of the cities as a function of north-south region and group. The upside-down white triangles in the approximate centers of the two circles in Canada are, from west to east, Edmonton and Ottawa. The symbols are defined as in Fig. 1, and error bars are standard errors of the means across subjects for each city. Subjects did not see any maps during the study; the North American map is overlaid on the grid in this figure for reference only. Note that the figure depicts only part of the stimulus array: The longitudes that appeared on each trial ranged from $0^{\circ}$ to $180^{\circ} \mathrm{W}$, and the latitudes ranged from $90^{\circ} \mathrm{N}$ to $40^{\circ} \mathrm{S}$

first used all of the estimates from the four north-to-south regions, and the second used only the eight farthest west and the seven farthest east Canadian cities (see Table 1), which we also used to test the reference point hypothesis.

For the analysis of all of the cities, there was only a main effect of region, $F(3,180)=3.94, \eta_{p}^{2}=.062$; all other $F_{\mathrm{s}}<$ 1.0. The means for all of the cities in each of the four regions, beginning with Canada, were $-9.27^{\circ},-7.31^{\circ},-9.18^{\circ}$, and $14.81^{\circ}$, respectively $\left(C I= \pm 4.54^{\circ}\right)$. The signed errors for both groups were all negative, and thus all too far to the west. From Fig. 2, it can be seen that neither the latitudes nor the longitudes were centered on the grid, so it is doubtful that subjects were using a "fill the space" or "center the space" strategy. Rather, it is more likely that the data were due to representational pseudoneglect by both groups.

The analysis of signed errors for the average signed error of the seven most eastern and eight most western Canadian cities also showed only a main effect of region, $F(1,60)=24.06$, $\eta_{p}^{2}=.286$. The means for the eastern and western cities were $1.47^{\circ}$ and $-16.11^{\circ}$, respectively $\left(C I= \pm 5.54^{\circ}\right)$.

Reference point analyses: estimated distances and knowledge ratings

For the analysis of the reference point effect, we first computed (from the location estimates) the estimated distance in kilometers for each possible pair of seven eastern Canadian cities and eight western cities, using the haversine formula, which computes the great-circle distance between two points. We then averaged these distances over eastern and western cities for each subject and conducted a Group $\times$ East/ West mixed ANOVA. Only the interaction was significant, $F(1,60)=6.68, \eta_{p}^{2}=.100$. The Edmontonians estimated the average distance between cities in the west versus the east as 1,685 versus $1,487 \mathrm{~km}$, whereas the Ottawans estimated the average distance as 1,763 versus $1,975 \mathrm{~km}$, respectively $(C I= \pm 158.27 \mathrm{~km})$. Thus, this was a crossover interaction, as would be predicted by the reference point hypothesis. The simple main effect between regions was significant for Edmonton, $F(1,31)=5.33, \eta_{p}^{2}=.147$, but not for Ottawa, $F(1,29)=2.43, p=.13, \eta_{p}^{2}=.077$, although the effect size was moderate, the means were in the right direction, and the order of magnitude of the difference was virtually identical to Edmonton's. The actual averaged distances between all pairs of seven eastern and eight western cities were 891 and $823 \mathrm{~km}$, so subjects were overestimating in general.

We next averaged the knowledge ratings for the seven eastern and eight western Canadian cities and analyzed them using the same design as for the distances. There was a main effect of region, $F(1,60)=85.88, \eta_{p}^{2}=$ .589 , and a Region $\times$ Group interaction, $F(1,60)=484.075$, $\eta_{p}^{2}=.890$. Edmontonians rated themselves as knowing more about western Canadian cities (5.81) than eastern Canadian cities (4.12), and Ottawans rated themselves as knowing more about eastern Canadian cities (6.42) than western Canadian cities (2.27), $C I= \pm 0.265$. The simple main effects were significant for both groups: for Edmonton, $F(1,31)=$ $119.25, \eta_{p}^{2}=.794$, and for Ottawa, $F(1,29)=359.36, \eta_{p}^{2}=$ 925. This finding supports the idea that the reference point effect can be supported by actual familiarity and not just by the mental point of view taken by the subjects, or even discriminability per se. It also supports the idea that the reference point effect is likely to be independent of the effects due to pseudoneglect. The notion of independence is also supported by one of Rode et al.'s (2010) findings: Their hemispatial neglect patient did not have trouble naming cities from the west of France, but did have trouble placing them correctly on a real or imagined map. 
It is important to reiterate that subjects saw the entire grid from $0^{\circ}-180^{\circ} \mathrm{W}$ on each trial. Thus, if they were trying to "center" their responses on the grid, their average longitude should have been about $90^{\circ}$. However, for both groups, the average estimates were significantly west of $90^{\circ}$ by about the same amount: For the Edmontonians, the mean estimate was $110.08^{\circ}, t(31)=5.99, C I=6.88^{\circ}$, and for the Ottawans it was $109.48^{\circ}, t(29)=5.38, C I=7.40^{\circ}$.

\section{General discussion}

The data from the present study show that both reference points and representational pseudoneglect affect biases in geographic location estimates. First, the evidence for the reference point effect was that there was more space between western than eastern cities for the Edmontonians, whereas the reverse was true for the Ottawans. Equally, knowledge ratings were higher for western than for eastern cities among the Edmontonians, whereas the reverse was true among the Ottawans. Second, both eastern and western Canadian university students displayed evidence of representational pseudoneglect in this new hemispatial attention paradigm, in which subjects had to estimate from memory the spatial locations of eastern (right-side) cities; hence, those cities could not be ignored, as right-sided landmarks can be when orally reporting from a mental image of a map or from a map itself (e.g., Rode \& Perenin, 1994; Rode, Rossetti, Perenin, \& Boisson, 2004). The findings thus support the representational pseudoneglect hypothesis using a more robust method than recall from a mental image: For our task, subjects could not leave out any of the cities (as if they were unseen or unattended to); they had to estimate all of them. That they erred toward the west could be due to hyperattentiveness to the left side or to neglect of the right (or both); our data do not allow us to discriminate between these two possibilities. But as subjects could not ignore the eastern cities and those cities were definitely not too far to the east, this is a new kind of evidence for representational pseudoneglect, because all of the stimuli that were on the right side of space had to be dealt with, and on a continuous scale. Under this circumstance, it was a priori plausible that the Ottawans would err too far to the east, but they did not. The present location estimate task is thus a novel test for representational pseudoneglect, because subjects must make estimates for all cities that they are presented with, left and right. This implies that they must use explicit knowledge about eastern cities to perform the task.

These results provide support for the proposition that both phenomena affect large-scale geographic location estimates. The data thus add to the literature on the representation of geographic space because, to our knowledge, no theory of geographical representation or processing (including our own) has taken into account representational pseudoneglect as a source of possible bias in location estimates. Furthermore, the fact that the reference point hypothesis was true of the Ottawans diminishes the possibility that representational pseudoneglect is purely an implicit attentional phenomenon, as has been shown in cases of actual neglect (Della Sala, van der Meulen, Bestelmeyer, \& Logie, 2010; Driver \& Vuilleumier, 2001; Vallar, 1998). In the present case, paying explicit attention to the right side of "memorial space" was required in order to respond to eastern cities. If the Ottawans had been inattentive or only implicitly attentive to eastern Canadian cities, they would not have been as likely to leave as much space between them as they actually did.

Thus, as far as we are aware, this is the first study to show representational pseudoneglect when subjects had to make responses to cities on the "neglected" side of space. The fact that they did so, and that the Ottawans showed a reference point effect for those cities, puts a different spin on the neglect phenomenon. That is, there was certainly a large western bias for the easterners, but some form of spatial knowledge was also used to space the eastern cities relatively far apart. If Ottawans were responding by "reading" from an imagined map of Canada, they were certainly not completely ignoring the right side of that image. This finding also has implications for the representation of world geography and for how we should interpret location estimates. For example, when estimating latitudes (both numerically and spatially), subjects appeared to use global landmarks (like the equator and the oceans) to divide the world into regions (Friedman, 2009; Friedman \& Brown, 2000a, 2000b). With longitudes and a spatial response mode, it appears that they may use higher-level hemispatial processes, as well as their home reference point, to "parse" space from east to west. This implies that different processes or strategies can impact the same spatial estimation task in the same person and can be responsible for different patterns of responding across individuals.

It should be noted that we and others have already shown that many factors affect geographical location estimates, including, but not limited to, global landmarks such as the oceans and the equator; what is learned throughout school and from other spoken and written sources; maps; attitudes toward others; and so on. Thus, it is possible in the present case that the relative sizes of the Atlantic and Pacific Oceans also influenced the east-west placement of the cities. However, were this the case, one might have imagined that the Baldwin illusion (Pressey \& Smith, 1986) would come into play and cause an eastward bias in both groups, as the Pacific Ocean is vastly wider (about four times, at the widest part) than the Atlantic. In the "pure" Baldwin illusion, a line flanked by two small squares is seen as longer than a line flanked by two large squares. Pressey and Smith found that, when a large square and a small square are placed on each 
side of a correctly bisected line, the portion of the line next to the smaller square appears to be longer than the one next to the larger square. Thus, either the subjects did not know that the Pacific is wider than the Atlantic, or the relative sizes of the oceans did not play any notable role here.

It should also be emphasized that the present data support the notion that representational pseudoneglect and the reference point effect are different psychological mechanisms. Thus, to "correct" for the reference point effect would be wrong (and we would have to somehow make the same kind of corrections for latitudes, which would not correspond to any traditional analysis in either the psychological or geographical literatures). For example, correcting for the reference point effect would not explain the westward bias that existed for both groups for their respective home cities. Like Holyoak and Mah (1982), Bisiach and Luzzatti (1978), Rode et al. (2010), and others, we believe that if we had asked our subjects to take a point of view from a different part of the country than where they lived, the form of the neglect would have shifted accordingly. For example, if we had them imagine that they were looking at a map of North America from the North Pole, eastern cities (which would be imagined on the left) should then show the pseudoneglect bias (e.g., Rode \& Perenin, 1994). Yet we would probably still see a reference point effect "surrounding" the home town of the subjects, because they probably do know more about places they live in and near than other places. These predictions will need to be addressed in future research.

An unexpected finding was that the two groups of subjects "parsed" their country differently from east to west. Ottawans put a relatively large distance between eastern Canada, the prairies, and the west coast. In contrast, Edmontonians had roughly three or four regions from west to east, and they were not spaced as far apart. We do not want to make much of this finding at this point, because we did not measure attitudes toward "others," which have previously been shown to play a role specifically in distance estimates (Carbon \& Leder, 2005) and map drawing (Lorenzi-Cioldi et al., 2011). However, such a systematic difference in students' mental geographies cannot be ignored in the investigation of any kind of visual neglect or geographical location estimates, because with real-world knowledge (as opposed to line bisection), factors other than perceptual ones may come into play in what is "seen" or not "seen." On this view, it might be possible to ameliorate the amount of true visual hemispatial neglect shown in impaired individuals by asking them to remember affect-laden events associated with items on the neglected side of space. Evidence for such affect-triggered implicit knowledge has been reported in the clinical literature (Marshall \& Halligan, 1988), and emotional cues can also shift the perceived midpoints of lines for healthy individuals (Mohr \& Leonards, 2007). The quantitative method introduced here may encourage a more in-depth exploration of the interactions between emotions and space more generally (Tamagni, Mantei, \& Brugger, 2009). In addition, recognition of reference point biases may enrich knowledge about both the behavioral neurology of the neglect syndrome and the processes underlying spatial location estimates.

Author Note This research was supported by a grant to A.F. from the Natural Sciences and Engineering Research Council of Canada. We thank Bernd Kohler for programming the experiment; Jo-Anne LeFevre for allowing us to collect the Ottawa data in her lab; Caitlyn Varenne, Velian Pandeliev, and Magda Piwowarczyk for collecting the data; and Chris Westbury for his comments on the manuscript.

\section{References}

Adair, J. C., \& Barrett, A. M. (2008). Spatial neglect: Clinical and neuroscience review. Annals of the New York Academy of Sciences, $1142,21-43$.

Bisiach, E., \& Luzzatti, C. (1978). Unilateral neglect of representational space. Cortex, 14, 129-133.

Bowers, D., \& Heilman, K. M. (1980). Pseudoneglect: Effects of hemispace on a tactile line bisection task. Neuropsychologia, 18, 491-498. doi:10.1016/0028-3932(80)90151-7

Brown, N. R., \& Siegler, R. S. (1993). Metrics and mappings: A framework for understanding real-world quantitative estimation. Psychological Review, 100, 511-534.

Carbon, C.-C., \& Leder, H. (2005). The Wall inside the brain: Overestimation of distances crossing the former Iron Curtain. Psychonomic Bulletin \& Review, 12, 746-750. doi:10.3758/BF03196767

Critchley, M. (1962). Clinical investigation of disease of the parietal lobes of the brain. Medical Clinics of North America, 46, 837857.

Della Sala, S., van der Meulen, M., Bestelmeyer, P., \& Logie, R. H. (2010). Evidence for a workspace model of working memory from semantic implicit processing in neglect. Journal of Neuropsychology, 4, 147-166. doi:10.1348/174866410X489679

Driver, J., \& Vuilleumier, P. (2001). Perceptual awareness and its loss in unilateral neglect and extinction. Cognition, 79, 39-88. doi:10.1016/S0010-0277(00)00124-4

Friedman, A. (2009). The role of categories and spatial cuing in globalscale location estimates. Journal of Experimental Psychology: Learning, Memory, and Cognition, 35, 94-112.

Friedman, A., \& Brown, N. R. (2000a). Reasoning about geography. Journal of Experimental Psychology: General, 129, 193-219. doi:10.1037/0096-3445.129.2.193

Friedman, A., \& Brown, N. R. (2000b). Updating geographical knowledge: Principles of coherence and inertia. Journal of Experimental Psychology: Learning, Memory, and Cognition, 26, 900-914. doi:10.1037/0278-7393.26.4.900

Friedman, A., Kerkman, D. D., Brown, N. R., Stea, D., \& Cappello, H. M. (2005). Cross-cultural similarities and differences in North Americans' geographic location judgments. Psychonomic Bulletin \& Review, 12, 1054-1060. doi:10.3758/BF03206443

Friedman, A., \& Montello, D. R. (2006). Global-scale location and distance estimates: Common representations and strategies in absolute and relative judgments. Journal of Experimental Psychology: Learning, Memory, and Cognition, 32, 333-346.

Halligan, P. W., Fink, G. R., Marshall, J. C., \& Vallar, G. (2003). Spatial cognition: Evidence from visual neglect. Trends in 
Cognitive Sciences, 7, 125-133. doi:10.1016/S1364-6613(03) 00032-9

Holyoak, K. J., \& Mah, W. A. (1982). Cognitive reference points in judgments of symbolic magnitude. Cognitive Psychology, 14, $328-352$.

Jewell, G., \& McCourt, M. E. (2000). Pseudoneglect: A review and meta-analysis of performance factors in line bisection tasks. Neuropsychologia, 38, 93-110.

Kahneman, D., \& Tversky, A. (1979). Prospect theory: An analysis of decision under risk. Econometrica, 47, 263-292.

Loetscher, T., \& Brugger, P. (2007). Exploring number space by random digit generation. Experimental Brain Research, 180, 655-665.

Lorenzi-Cioldi, F., Chatard, A., Marques, J. M., Selimbegović, L., Conan, P., \& Faniko, K. (2011). Social Psychology, 42, 234-240.

Marshall, J. C., \& Halligan, P. W. (1988). Blindsight and insight in visuo-spatial neglect. Nature, 336, 766-767. doi:10.1038/ $336766 \mathrm{a} 0$

Masson, M. E. J., \& Loftus, G. R. (2003). Using confidence intervals for graphically based data interpretation. Canadian Journal of Experimental Psychology, 57, 203-220. doi:10.1037/h0087426

McGeorge, P., Beschin, N., Colnaghi, A., Rusconi, J. L., \& Della Sala, S. (2007). A lateralized bias in mental imagery: Evidence for representational pseudoneglect. Neuroscience Letters, 421, 259-263.

Mohr, C., \& Leonards, U. (2007). Rightward bisection errors for letter lines: The role of semantic information. Neuropsychologia, 45, 295-304.

Oldfield, R. C. (1971). The assessment and analysis of handedness: The Edinburgh inventory. Neuropsychologia, 9, 97-113. doi:10.1016/0028-3932(71)90067-4
Pressey, A. W., \& Smith, N. E. (1986). The effects of location, orientation, and cumulation of boxes in the Baldwin illusion. Perception \& Psychophysics, 40, 344-350. doi:10.3758/BF03203026

Rode, G., Cotton, F., Revol, P., Jacquin-Courtois, S., Rossetti, Y., \& Bartolomeo, P. (2010). Representation and disconnection in imaginal neglect. Neuropsychologia, 48, 2903-2911. doi:10.1016/j. neuropsychologia.2010.05.032

Rode, G., \& Perenin, M.-T. (1994). Temporary remission of representational hemineglect through vestibular stimulation. NeuroReport, 5, 869-872.

Rode, G., Rossetti, Y., Perenin, M.-T., \& Boisson, D. (2004). Geographic information has to be spatialised to be neglected: A representational neglect case. Cortex, 40, 391-397. doi:10.1016/ S0010-9452(08)70133-3

Stevens, A., \& Coupe, P. (1978). Distortions in judged spatial relations. Cognitive Psychology, 10, 422-437.

Tamagni, C., Mantei, T., \& Brugger, P. (2009). Emotion and space: Lateralized emotional word detection depends on line bisection bias. Neuroscience, 162, 1101-1105.

Vallar, G. (1998). Spatial hemineglect in humans. Trends in Cognitive Science, 2, 87-97.

Verdon, V., Schwartz, S., Lovblad, K.-O., Hauert, C.-A., \& Vuilleumier, P. (2010). Neuroanatomy of hemispatial neglect and its functional components: A study using voxel-based lesion-symptom mapping. Brain, 133, 880-894.

Vuilleumier, P., Ortigue, S., \& Brugger, P. (2004). The number space and neglect. Cortex, 40, 399-410. doi:10.1016/S0010-9452(08) 70134-5

Zorzi, M., Priftis, K., \& Umiltà, C. (2002). Brain damage: Neglect disrupts the mental number line. Nature, 417, 138-139. doi:10.1038/417138a 